\title{
Transmitral velocities measured by pulsed Doppler in healthy volunteers: effects of acute changes in blood pressure and heart rate
}

\author{
S A SMITH, J E STONER, A E RUSSELL, J M SHEPPARD, P E AYLWARD \\ From the Department of Medicine, Flinders Medical Centre, Bedford Park, South Australia
}

SUMMARY The effect of a two minute cold pressor test on transmitral velocities measured by pulsed Doppler was studied in 11 healthy volunteers. Blood pressure increased significantly during cold immersion but peak atrial and peak early diastolic transmitral velocities and their ratio (A:E) were unchanged. There was no correlation between changes in Doppler variables and changes in calculated mean arterial blood pressure during the test. Heart rate changes were variable and not related to changes in blood pressure. In individual people the change in pulse interval during cold immersion was significantly and inversely correlated with the change in the A:E ratio.

The large acute increase in arterial pressure seen during the cold pressor test in normal volunteers had no consistent effect on the transmitral velocity profile although small changes in heart rate were associated with large changes in $A: E$ ratio. The effect of small changes in heart rate may be of considerable importance in determining transmitral velocity profiles. Thus in clinical and experimental studies in which the heart rate is not controlled, Doppler data on transmitral flow should be interpreted with caution.

Alterations in transmitral velocities measured by Doppler, particularly the ratio of peak atrial to peak early diastolic flow (A:E ratio), have been attributed to abnormal left ventricular relaxation. ${ }^{12}$ Pulsed Doppler echocardiography has been widely used to examine left ventricular diastolic function in people with hypertension, ${ }^{3}$ hypertrophic cardiomyopathy, and ischaemic heart disease. ${ }^{5}$

Recently it has been recognised that factors other than myocardial disease, including age, ${ }^{67}$ left ventricular preload, ${ }^{8}$ end diastolic pressure, ${ }^{9}$ and Doppler sample site $^{10}$ may alter transmitral flow measurements.

Two studies of invasive measurements of haemodynamic variables in dogs suggested that the rate of left ventricular relaxation may be partly determined by left ventricular afterload. ${ }^{112}$ There are no data on the effect of acute changes in afterload on transmitral velocity measured by Doppler in healthy people.

Requests for reprints to: Dr P E Aylward, Department of Medicine, Flinders Medical Centre, Bedford Park, South Australia 5042, Australia.

Accepted for publication 8 December 1988
We examined the effect of a standard cold pressor test, which produces large changes in blood pressure, and thus afterload, ${ }^{13}$ on transmitral velocity in healthy volunteers.

\section{Patients and methods}

We studied 11 untreated, healthy volunteers (eight men, three women, mean (SD) age of 34.4 (5.9) years, range 24 to 44 years). They had no history of hypertension, cardiovascular disease, or excessive alcohol consumption.

PROTOCOL

All measurements were made in a quiet laboratory with a constant ambient temperature of $21^{\circ} \mathrm{C}$. Volunteers were positioned in a left lateral semirecumbent position and this was adjusted until optimal Doppler recordings were obtained: thereafter the volunteers' position was not changed. After they had rested for 10 minutes they immersed their right hands in melting ice for two minutes. Blood pressure was recorded indirectly with a standard mercury sphygmomanometer and heart rate was measured from the electrocardiogram. The mean blood pres- 
sure was calculated as diastolic pressure plus one third of the pulse pressure.

\section{DOPPLER RECORDING AND ANALYSIS}

Pulsed Doppler examinations of transmitral flow were recorded continuously on videotape throughout the cold pressor test on a Diasonics CV 400 ultrasound system with a transducer emission frequency of 3.0 MHz. The Doppler sample volume was placed, without angle correction, in the mitral valve funnel just to the left ventricular side of the mitral annulus and with the ultrasound beam as parallel as possible to left ventricular inflow.

We analysed the Doppler profiles recorded immediately before the cold pressor test, at one and two minutes during the test, and one minute after the test. Peak early diastolic velocity $(E)$, peak atrial velocity $(A)$, their ratio (A:E), and the corresponding pulse intervals $(R R)$ were averaged over five consecutive cardiac cycles.

Data were expressed as mean (SD). Formal tests of statistical significance were obtained by standard methods of analysis of variance and linear regression analysis. Statistical significance is reported for $p$ values of $<0.05$.
Table 1 Peak atrial $(A)$ and early $(E)$ diastolic velocities, their ratio $(A: E)$, pulse interval $(R R)$, and mean blood pressure (MBP) measured before, after one and two minutes of a cold pressor test, and one minute after the end of the test

\begin{tabular}{|c|c|c|c|c|c|}
\hline & $\underset{(m / s)}{A}$ & $\begin{array}{l}E \\
(\mathrm{~m} / \mathrm{s})\end{array}$ & $A: E$ & $\begin{array}{l}R R \\
(m s)\end{array}$ & $\begin{array}{l}M B P \\
(m m H g)\end{array}$ \\
\hline $\begin{array}{l}\text { Before } \\
1 \text { min } \\
2 \text { min } \\
\text { After }\end{array}$ & $\begin{array}{l}0.42(0.02) \\
0.46(0.03) \\
0.45(0.03) \\
0.42(0.04)\end{array}$ & $\begin{array}{l}0.62(0.04) \\
0.62(0.04) \\
0.66(0.04) \\
0.66(0.03)\end{array}$ & $\begin{array}{l}0.72(0.08) \\
0.79(0.10) \\
0.79(0.11) \\
0.65(0.08)\end{array}$ & $\begin{array}{l}872(48) \\
857(46) \\
901(52) \\
899(32)\end{array}$ & $\begin{array}{c}81(2) \\
101(3)^{\star} \\
102(3)^{\star} \\
86(3)\end{array}$ \\
\hline
\end{tabular}

${ }^{\star} \mathrm{p}<0.001$ compared with values before test.

\section{Results}

HAEMODYNAMIC EFFECTS OF THE COLD PRESSOR TEST

Mean arterial blood pressure increased by approximately $20 \mathrm{~mm} \mathrm{Hg}(\mathrm{p}<0.001)$ during the cold pressor test (table) and returned to pretest values within one minute of the removal of the hand from the ice. Heart rate did not change significantly during the cold pressor test and we found no relation between changes in heart rate and blood pressure.
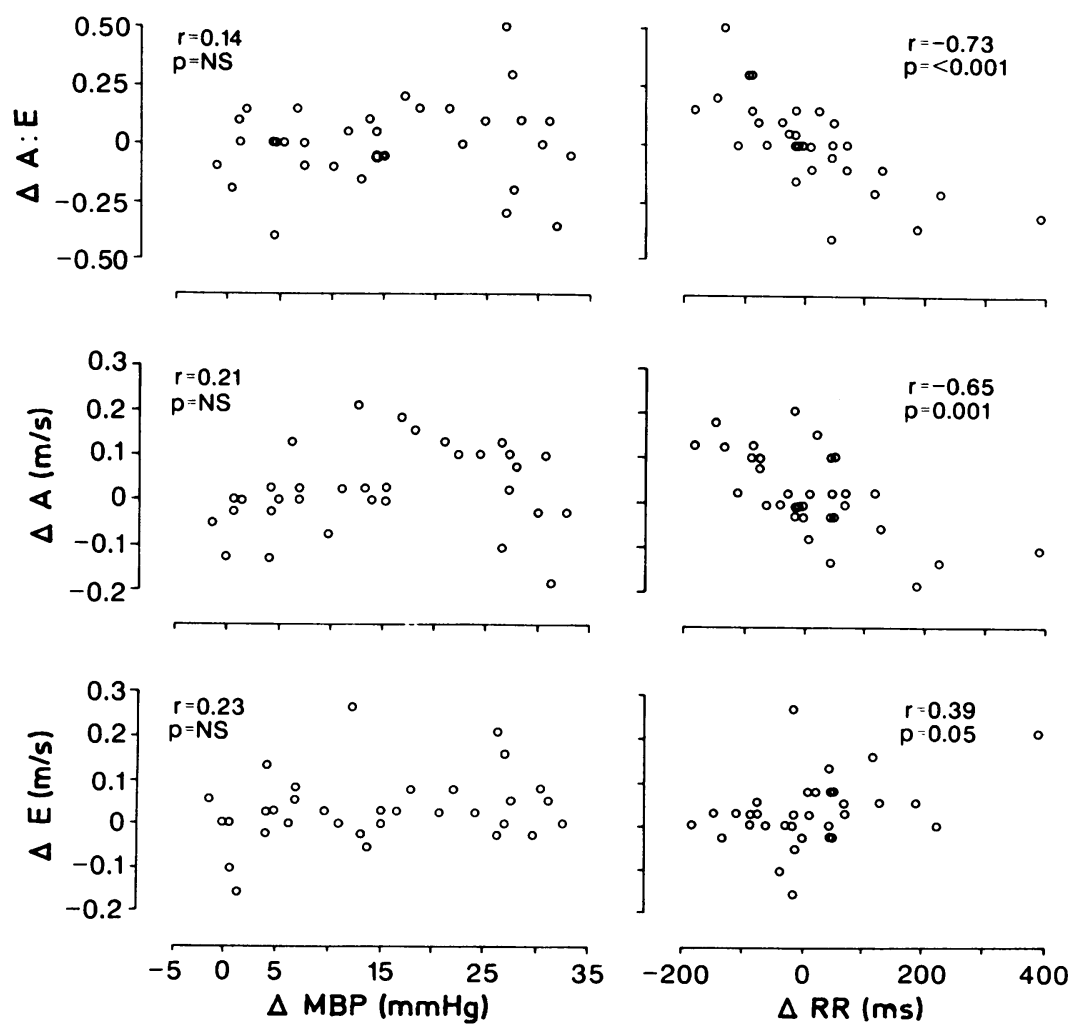

Relations between individual changes from baseline of mean blood pressure ( $M B P$ ) and pulse interval ( $R R$ ) and individual changes in peak early $(E)$ and atrial $(A)$ diastolic transmitral velocities and their ratio ( $A: E$ ) during ( 1 and 2 minutes) and after (1 minute) the cold pressor test in eleven healthy individuals. 
DOPPLER VARIABLES AND THEIR RELATION TO BLOOD PRESSURE

There were no significant changes in peak atrial velocity $(A)$, peak early diastolic velocity $(E)$, or $A: E$ ratio at any stage of the cold pressor test despite a 20 $\mathrm{mm} \mathrm{Hg}$ increase in mean arterial pressure. The changes in mean arterial blood pressure within individuals did not correlate with changes in $A, E$, or A:E (figure).

\section{DOPPLER VARIABLES AND THEIR RELATION TO} HEART RATE

Though heart rate did not change during or after the cold pressor test in the group as a whole, the heart rate increased in some individuals and decreased in others. Changes in $A: E$ within each individual correlated significantly with the change in $\mathbf{R} R$ (figure). This correlation was mainly the result of an inverse relation between changes in $R R$ and in peak atrial velocity (A), though a less striking, but still statistically significant, positive correlation was noted between changes in $R R$ and in peak early diastolic velocity.

\section{Discussion}

This study shows that transmitral velocity measured by Doppler is not affected by large changes in arterial pressure but it is considerably affected by small changes in heart rate.

The cold pressor test reliably increases blood pressure with small or inconsistent effects on other relevant haemodynamic variables. ${ }^{13} \mathrm{We}$ used the cold pressor test to assess the effects of acute changes in blood pressure on transmitral velocities measured by Doppler. Analysis of transmitral flow by Doppler has been advocated as a method for examining left ventricular diastolic function ${ }^{12}$ and animal experiments have suggested that the rate of left ventricular relaxation may be partly determined by afterload. ${ }^{11} 12$ The original purpose of this study was to examine the effects of changes in blood pressure on Doppler variables in order to determine whether such changes need to be taken into account when serial Doppler examinations are interpreted.

Because we were unable directly to measure changes in central haemodynamic variables in this noninvasive study we cannot exclude changes in preload in our study group, but earlier work suggests that changes in preload are likely to be small. ${ }^{13}$ Because the experiment was performed in conscious people, a direct effect of increased afterload on left ventricular relaxation (and thus Doppler transmitral velocity) may have been opposed by reflex effects. Whatever the mechanism, we found no consistent relation between large acute changes in blood pressure and
Smith, Stoner, Russell, Sheppard, Aylward $\underset{\mathbb{\Phi}}{\stackrel{\square}{\square}}$ changes in Doppler variables, suggesting that changes in afterload can be ignored in an interpretation of $\subseteq$ Doppler measures of mitral flow. Our data do not $\overrightarrow{\overline{\vec{S}}}$ exclude the possibility of a small effect of blood $\frac{\sigma}{0}$ pressure variation on Doppler variables, but any such effect would be of little importance in practice. Further studies are required before conclusions can be drawn about the effects of acute changes in blood pressure in patients with cardiovascular disease.

We found that the peak velocity of the atrial $\vec{\circ}$ component of diastolic flow was inversely related to the pulse interval within individuals. Our data suggest that a small change in heart rate from $\mathbf{7 0}$ to $\mathbf{8 0}$ beats/min would increase the ratio of peak atrial to peak early diastolic transmitral velocity $(\mathrm{A}: \mathrm{E})$ by approximately $30 \%$. Other studies that have specifically examined the effects of changes in heart rate on transmitral velocities measured by Doppler have shown similarly pronounced effects of heart rate. Gillam et al using programmed pacing showed a tenfold change in E:A ratio as heart rate was changed from 60 to 100 beats $/ \mathrm{min} .{ }^{14}$ Parker et al using atropine showed a similar dependency of A:E on heart rate. ${ }^{15}$ This relation between changes in heart rate and in peak atrial velocity and A:E ratio may be of considerable clinical and experimental importance. Reliable correction for changes in heart rate between sequential studies will not be possible until the precise relation between heart rate and transmitral flow is fully established. There are many published reports of changes in A:E after procedures such as coronary angioplasty, ${ }^{1617}$ head up tilting, ${ }^{18}$ and administration of vasoactive drugs. ${ }^{819}$ The results of such studies may not be valid if the heart rate changed between the Doppler examinations.

Serial measurements of transmitral velocity profiles are not significantly affected by large changes in blood pressure in healthy volunteers. In clinical and experimental studies in which the heart rate changes, Doppler data on transmitral velocity should be interpreted with caution.

SAS was a British Heart Foundation/Australian National Heart Foundation reciprocal travelling fellow. AER holds a Lions Postgraduate Medical Research Scholarship. We thank Mrs S Taylor for her assistance with analysis of the data and the illustrations.

\section{References}

1 Snider AR. Prediction of intracardiac pressures and assessment of ventricular function with Doppler echocardiography. Echocardiography 1987;4:305-20.

2 DeMaria $A N$, Wisenbaugh $T$. Identification and treatment of diastolic dysfunction: role of transmitral 
Doppler recordings. J Am Coll Cardiol 1987;9: 1106-7.

3 Snider AR, Gidding SS, Rocchini AP, et al. Doppler evaluation of left ventricular diastolic filling in children with systemic hypertension. Am J Cardiol 1985;56:921-6.

4 Maron BJ, Spirito P, Green KJ, Wesley YE, Bonow RO, Arce J. Noninvasive assessment of left ventricular diastolic function by pulsed Doppler echocardiography in patients with hypertrophic cardiomyopathy. J Am Coll Cardiol 1987;10:733-42.

5 Harrison MR, Smith MD, Friedman BJ, DeMaria AN. Uses and limitations of exercise Doppler echocardiography in the diagnosis of ischaemic heart disease. J Am Coll Cardiol 1987;10:809-17.

6 Miller TR, Grossman SJ, Schectman KB, Biello DR, Ludbrook PA, Ehsani AA. Left ventricular diastolic filling and its association with age. Am J Cardiol 1986;58:531-5.

7 Kuo LC, Quinones MA, Rokey R, Sartori M, Abinader EG, Zoghbi WA. Quantification of atrial contribution to left ventricular filling by pulsed Doppler echocardiography and the effect of age in normal and diseased hearts. J Am Cardiol 1987;59:1174-8.

8 Choong CY, Herrmann HC, Weyman AE, Fifer MA. Preload dependence of Doppler derived indices of left ventricular diastolic function in humans. $\mathrm{J} \mathrm{Am} \mathrm{Coll}$ Cardiol 1987;10:800-8.

9 Channer KS, Culling W, Wilde P, Jones JV. Estimation of left ventricular end diastolic pressure by pulsed Doppler ultrasound. Lancet 1986;i:1005-7.

10 Gardin JM, Dabestani A, Takenaka K, et al. Effect of imaging view and sample volume location on evaluation of mitral flow velocity by pulsed Doppler echocardiography. Am J Cardiol 1986;57:1135-9.

11 Gaash WH, Blaustein AS, Andrias CW, Donahue RP, Avitall B. Myocardial relaxation. II. Hemodynamic determinants of rate of left ventricular isovolumic pressure decline. Am J Physiol 1980;239:H1-6.

12 Karliner JS, LeWinter MM, Mahler F, Engler R, O'Rourke RA. Pharmacologic and hemodynamic influences on the rate of isovolumic left ventricular relaxation in the normal conscious dog. $J$ Clin Invest 1977;60:511-22.

13 Greene MA, Boltax AJ, Lustig GA, Rogow E. Circulatory dynamics during the cold pressor test. $\mathrm{Am} \mathrm{J}$ Cardiol 1965;16:54-60.

14 Gillam DL, Shunichi H, Novick SS, Rediker DE, Eagle KA. The influence of heart rate Doppler mitral flow patterns [Abstract]. Circulation 1987;76(suppl IV): IV-123.

15 Parker TG, Cameron D, Serra J, Morgan CD, Sasson $Z$. The effect of heart rate and $A-V$ interval on Doppler ultrasound indices of $\mathrm{LV}$ diastolic function [Abstract]. Circulation 1987;76(suppl IV):IV-124.

16 Wind BE, Snider AR, Buda AJ, O'Neill WW, Topol EJ, Dilworth LR. Pulsed Doppler assessment of left ventricular diastolic filling in coronary artery disease before and immediately after coronary angioplasty. Am J Cardiol 1987;59:1041-6.

17 Labovitz AJ, Lewen MK, Kern M, et al. Evaluation of left ventricular systolic and diastolic dysfunction during transient myocardial ischaemia produced by angioplasty. J Am Coll Cardiol 1987;10:748-55.

18 Leeman DE, Feldman MD, Diver DJ, Santinga JT, Come PC. Effects of decreases in preload on pulsed Doppler indices of left ventricular filling [Abstract]. Circulation 1986;74(suppl II):II-46.

19 Iwase M. Sotobata I, Takagi S, Miyaguchi K, Jing HX, Yokota M. Effects of diltiazem on left ventricular diastolic behaviour in patients with hypertrophic cardiomyopathy: evaluation with exercise pulsed Doppler echocardiography. J Am Coll Cardiol 1978;9:1099-105. 